\title{
PENERAPAN LEAN MANUFACTURING GUNA MEMINIMASI WASTE PADA LANTAI PRODUKSI (Studi Kasus: UD. FILKIN)
}

\author{
M. L. Pattiapon, \\ Program Studi Teknik Industri, Fakultas Teknik Universitas Pattimura, Ambon \\ N. E. Maitimu \\ Program Studi Teknik Industri, Fakultas Teknik Universitas Pattimura, Ambon \\ Irene Magdalena \\ Program Studi Teknik Industri, Fakultas Teknik Universitas Pattimura, Ambon
}

\begin{abstract}
ABSTRAK
UD. Filkin adalah salah satu perusahaan industri yang bergerak di bidang mebel. Salah satu produknya adalah pintu. Dalam produksinya, terdapat berbagai jenis waste yang sering terjadi tanpa disadari, karena telah dianggap sebagai sesuatu yang wajar dan umum, padahal sesungguhnya sangat merugikan, dan seharusnya bisa dihindari, sehingga pada hasil identifikasi ditemukan beberapa jenis waste yang diantaranya waiting, innappropiateprocessing dan overproduction.Maka tujuan penelitian ini adalah untuk mengidentifikasi dan mengevaluasi penyebab waste yang terjadi dalam lantai produksi, dan juga memberikan rekomendasi perbaikan untuk mengurangi waste di lantai produksi. Salah satu metode yang dapat digunakan untuk mengurangi atau mengeliminasi waste adalah dengan metode Lean Manufacturing.Pendekatan Lean Manufacturing dilakukan dengan menganalisis waste dengan value stream mapping, menentukan waste dan mengidentifikasi akar penyebab masalah atau peristiwa dengan root cause analysis, dan merancang rekomendasi perbaikan untuk mengatasi waste tersebut.Berdasarkan hasil penelitian diketahui bahwa tiga waste dengan rangking tertinggi adalah waiting dengan skor $(17,1 \%)$, innappropiateprocessing $(16,5 \%)$ dan overproduction $(15,9 \%)$. Sehingga untuk mengurangi wastewaiting disarankan agar melakukan pelatihan dan penambahan pekerja. Untuk mengurangi wasteinnappropiateprocessing disarankan untuk meningkatkan pola pemahaman pekerja terhadap keinginan konsumen. Dan untuk mengurangi waste overproduction disarankan untuk melakukan perencanaan ulang terhadap produk yang akan dibuat, yang sesuai dengan permintaan pasar.
\end{abstract}

Kata Kunci: Waste, Lean Manufacturing, Value Stream Mapping

\begin{abstract}
UD. Filkin is one of the industrial companies engaged in furniture business, i. e. door. There are various types of waste yielded in production that often occur unnoticed. It has been considered as something that is reasonable and common, when in fact it is very detrimental, and should be avoided. It causes several types of waste including waiting, inappropriate processing and overproduction. The purpose of this study is to identify and evaluate the causes of waste that occur in the production floor, and also provide recommendations for improvements to reduce waste on the production floor. A method that has be used to reduce or eliminate waste is the Lean Manufacturing method. This method is done by analyzing waste with value stream mapping, determining waste and identifying the root causes of problems or events with root cause analysis, and designing recommendations for improvement to overcome waste. According to results of the study, the three highest ranking wastes are waiting (17.1\%), inappropriate processing $(16.5 \%)$ and overproduction $(15.9 \%)$. It is suggested, in order to reduce waste, to train and add workers (waiting), improve workers' understanding patterns of consumer desires (inappropriate processing), and re-plan products to be made, which are in accordance with market demand (overproduction).
\end{abstract}

Keywords: Waste, Lean Manufacturing, Value Stream Mapping 


\section{PENDAHULUAN}

Dalam perekonomian global yang semakin kompetitif, setiap industri ditantang untuk menghasilkan produk yang berkualitas baik. Selain itu hanya produk yang berkualitas baik yang akan selalu diminati, karena kualitas merupakan pemenuhan pelayanan kepada konsumen. Untuk mencapai tujuan tersebut maka perusahaan perlu membuat proses produksi menjadi optimal.

UD. Filkin adalah salah satu perusahaan industri yang bergerak di bidang mebel. Produk yang dihasilkan oleh UD. Filkin adalah furniture seperti meja, kursi, lemari, jendela dan pintu. Kayu yang digunakan oleh UD. Filkin ini yaitu kayu linggua dan kayu besi yang di kirim langsung dari pulau Seram. Berdasarkan hasil wawancara dan observasi lapangan, pada UD. Filkin terdapat beberapa faktor yang mengakibatkan terjadinya pemborosan terhadap waktu, tenaga, jarak, material, dan mesin.

Kondisi ini apabila terjadi secara terus-menerus akan berpengaruh terhadap efisiensi dan produktivitas perusahaan, yang nantinya dapat merugikan perusahaan. Untuk itu, penerapan metode yang sesuai sangat diperlukan untuk mengidentifikasi tingkat pemborosan atau waste sehingga mampu menekan atau bahkan bisa mengurangi kegiatan atau aktifitas yang tidak bernilai tambah (non value added activity). Analisa yang dilakukan untuk mengidentifikasi setiap waste yang terjadi pada UD. Filkin menggunakan metode Root Cause Tool dan metode Lean Manufacturing yang akan dipakai untuk mengevaluasi setiap waste dan dapat memberikan usulan perbaikan bagi perusahaan.

Metode Root Cause Analysis atau analisis akar penyebab adalah sebuah kelas dari pemecahan masalah metode yang bertujuan untuk mengidentifikasi akar penyebab masalah atau peristiwa. Sedangkan untuk metode Lean Manufacturing merupakan metode yang melakukan eliminasi terhadap pemborosan yang ditemukan pada aliran proses produksi.

Berdasarkan permasalahan diatas dapat disimpulkan bahwa perusahaan membutuhkan pemecahan masalah yang dihadapi pada lantai produksi untuk mengurangi pemborosan yang sering terjadi. Oleh sebab itu pendekatan Lean Manufacturing sangat menunjang untuk meminimalisasi atau mengeliminasi waste sehingga dapat meningkatkan produktivitas.

Adapaun tujuan yang ingin di capai dalam penelitian ini adalah : 1. Mengidentifikasi dan mengevaluasi setiap waste yang terjadi pada UD. Filkin sehingga dapat mengetahui faktor-faktor penyebab waste yang harus perlu diperbaiki; 2 . Merumuskan rekomendasi perbaikan untuk meningkatkan produktifitas dan mengurangi waste yang terjadi pada sistem produksi pintu

\section{LANDASAN TEORI}

Prinsip utama dari pendekatan lean adalah untuk mengurangi atau meniadakan pemborosan (Pujawan, 2002). Istilah "lean“ yang dikenal luas dalam dunia manufaktur dewasa ini dikenal dalam berbagai nama yang berbeda seperti: lean production, lean manufacturing, toyota production system, dan lain-lain. Meskipun demikian, lean dipercaya oleh sebagian orang dikembangkan di Jepang, khususnya Toyota sebagai pelopor sistem lean manufacturing.

Tujuan dari lean manufacturing adalah untuk membangun dan merancang sebuah manufaktur yang mampu memproduksi beberapa produk dengan menggunakan jumlah waktu yang benar-benar dibutuhkan membuat produk. Menunggu, waktu antrian, dan penundaan lainnyadianggap pemborosan dan sangat diminimumkan atau dihilangkan dalam lean manufacturing (Hobbs, 2004).

\section{Munculnya Lean Production}

Istilah "Lean" yang dikenal luas dalam dunia manufacturing dewasa ini dikenal dalam berbagai nama yang berbeda seperti: Lean Production, Lean Manufacturing, Toyota Production System, dan lainlain. (Khannan danHaryono,2015)

\section{Value Stream Mapping(VSM)}

Tujuan dari VSM adalah mendapatkan suatu proses untuk menentukan proses apa saja yang dibutuhkan selanjutnya. VSM adalah sebuah teknik perbaikan perusahaan untuk menggambarkan seluruh proses produksi, yang meliputi aliran informasi dan material, dalam rangka meningkatkan proses produksi dan mengidentifikasi sumber pemborosan. Teknik penggambaran peta aliran material dan informasi dimulai dari waktu bahan baku masuk kedalam jalur produksi, hingga menjadi produk jadi (Widjaja dan Halim, 2015).

\section{Macam-Macam Waste}

Waste adalah segala aktifitas dalam proses kerja yang tidak memberikan nilai tambah bagi produk. Minimasi pemborosan merupakan hal yang penting untuk mendapatkan value stream yang baik. Berikut ini penjelasan mengenai tujuh tipe-tipe pemborosan menurut Shingo (1990), yaitu:

1. Overproduction (produksi berlebih),

2. Waiting (menunggu), 
3. Transportation (transportasi berlebih),

4. Overprocessingor Incorrect Processing (proses tidak sesuai),

5. Unnecessary Inventory (persediaan tidak perlu),

6. Unnecessary Motion (gerakan tidak perlu),

7. Defects (produk cacat),

Apabila membahas mengenai pemborosan, maka perlu didefinisikan tiga jenis aktifitas yang terjadi

di dalam suatu sistem produksi (Hines, 2008). Ketiga jenis aktifitas tersebut, yaitu:

1. Aktifitas yang memberikan nilai tambah,

2. Aktifitas yang tidak memberikan nilai tambah,

3. Aktifitas yang tidak memberikan nilai tambah tapi dibutuhkan.

Big Picture Mapping

Langkah-langkah dalam menggambar Big Picture Mapping adalah sebagai berikut :

1. Menggambarkan kebutuhan konsumen (customer),

2. Menggambarkan aliran informasi dari customer ke supplier,

3. Menggambarkan aliran fisik terjadi, dititik mana inspeksi dilakukan, waktu penyelesaian tiap operasi, dan sebagainya.

4. Menghubunngkan aliran informasi dan aliran fiik dengan anak panah yang dapat memberikan informasi jadwal yang digunakan, instruksi kerja yang dihasilkan, dari dan untuk apa informasi dan instruksi dikirim, kapan dan dimanabiasanya terjadi masalah dalam aliran fisik.

5. Melengkapi peta atau gambar aliran informasi dan aliran fisik yang dilakukan dengan menambahkan lead time dan value adding time dibawah gambar aliran yang dibuat.

Value Stream Mapping Tools (VALSAT)

VALSAT merupakan sebuah pendekatan yang digunakan denganmelakukan pembobotan waste, kemudian dari pembobotan tersebut dilakukan pemilihan terhadap tool dengan menggunakan matrik. Terdapat 7 tools yang bisa digunakan, yaitu: Process Activity Mapping, Supply Chain Response Matrix, Production Variety Funnel, Quality Filter Mapping, Demand Amplification Mapping, Decission Point Analysis, dan Physical Structure. Perlu dipahami bahwa setiap tool mempunyai kelebihan dan kekurangan tersendiri dalam mengidentifikasi suatu jenis waste tertentu. ( Batubara, dan Halimuddin, 2016).

\section{Diagram Sebab Akibat}

Diagram sebab akibat menggambarkan garis-garis dan simbol-simbol yang menunjukan hubungan antra akibat dan penyebab suatu masalah untuk selanjutnnya diambil tindakan perbaikan. Dari akibat tersebut kemudian dicari beberapa kemungkinan penyebabnya. Penyebab masalah ini pun dapat berasal dari berbagai sumber sumber utama, misalnya metode kerja alat dan bahan, pengukuran, karyawan, lingkungan dan sebagainya.

\section{Diagram Pareto}

Diagram pareto adalah grafik batang yang menunjukkan masalah berdasarkan urutan banyaknya jumlah kejadian. Hal ini dapat membantu menemukan permasalahan yang paling penting untuk segera diselesaikan (rangking tertinggi) sampai dengan masalah yang tidak harus segera diselesaikan (rangking terendah) (Ariani, 2004).

\section{Root Cause Tools}

Terdapat 4 langkah dalam RCA, yaitu:

1. Mengidentifikasi dan memperjelas definisi undesired outcome (suatu kejadiaan yang tidak diharapkan).

2. Mengumpulkan data.

3. Menempatkan kejadian-kejadian dan kondisi-kondisi pada event andcausal factor table. Lanjutkan pertanyaan "mengapa" untuk mengidentifikasi root causes yang paling kritis.

\section{METODE PENELITIAN}

\section{Metode Pengolahan Data}

Adapun pengolahan data yang dilakukan dalam penelitian berikut :

1. Membuat Big Picture Mapping, yang dapat memberikan pemahaman akan sistem produksi perusahan secara keseluruhan juga Value Streamsehingga diperoleh gambaran mengenai aliran fisik dan aliran informasi dari sistem yang ada. 
2. Melakukan identifikasi waste, yang dilakukan pembobotan waste yang terdapat disepanjang value stream. Nilai pembobotan diperoleh dari hasil penyebaran kuesioner, dimana nilai bobot berkisar antara 1 sampai 10.

3. Melakukan identifikasi waste dengan diagram pareto, dengan menggunakan hasil yang didapat dari penyebaran kuesioner. Dimana hasil yang ditunjukkan berdasarkan urutan banyaknya jumlah kejadian.

4. Memilih Value Stream mapping tool, dengan menggunakan Value Stream Analysis Tools (VALSAT)

\section{Metode Analisa Data}

Adapun pengolahan data yang dilakukan dalam penelitian berikut :

1. Memilih Value StreamMapping Tool, dengan menggunakan Value Stream Analysis Tools (VALSAT). Dari tabel VALSAT, akan dipilih beberapa tools dengan skor kumulatif terbesar dengan memastikan bahwa setiap waste yang terjadi terakomodasi oleh mapping.

2. Menganalisa penyebab waste menggunakan Fishbone Diagram dan Root Cause Tools sebagai alat ukur yang sesuai untuk mengidentifikasi penyebab terjadi permasalahan. Tahap analisa ini dilakukan berdasarkan waste yang teridentifikasi, dengan mencari akar penyebab dari waste itu sendiri dengan menggunakan beberapa metode.

3. Setelah diketahui penyebab terjadinya waste, kemudian dibuat rekomendasi perbaikan yang sesuai untuk menghilangkan waste yang ada guna meningkatkan produktifitas pada perusahan serta dapat meningkatkan profit pada perusahan.

Berikut ini adalah flowchart penelitian:

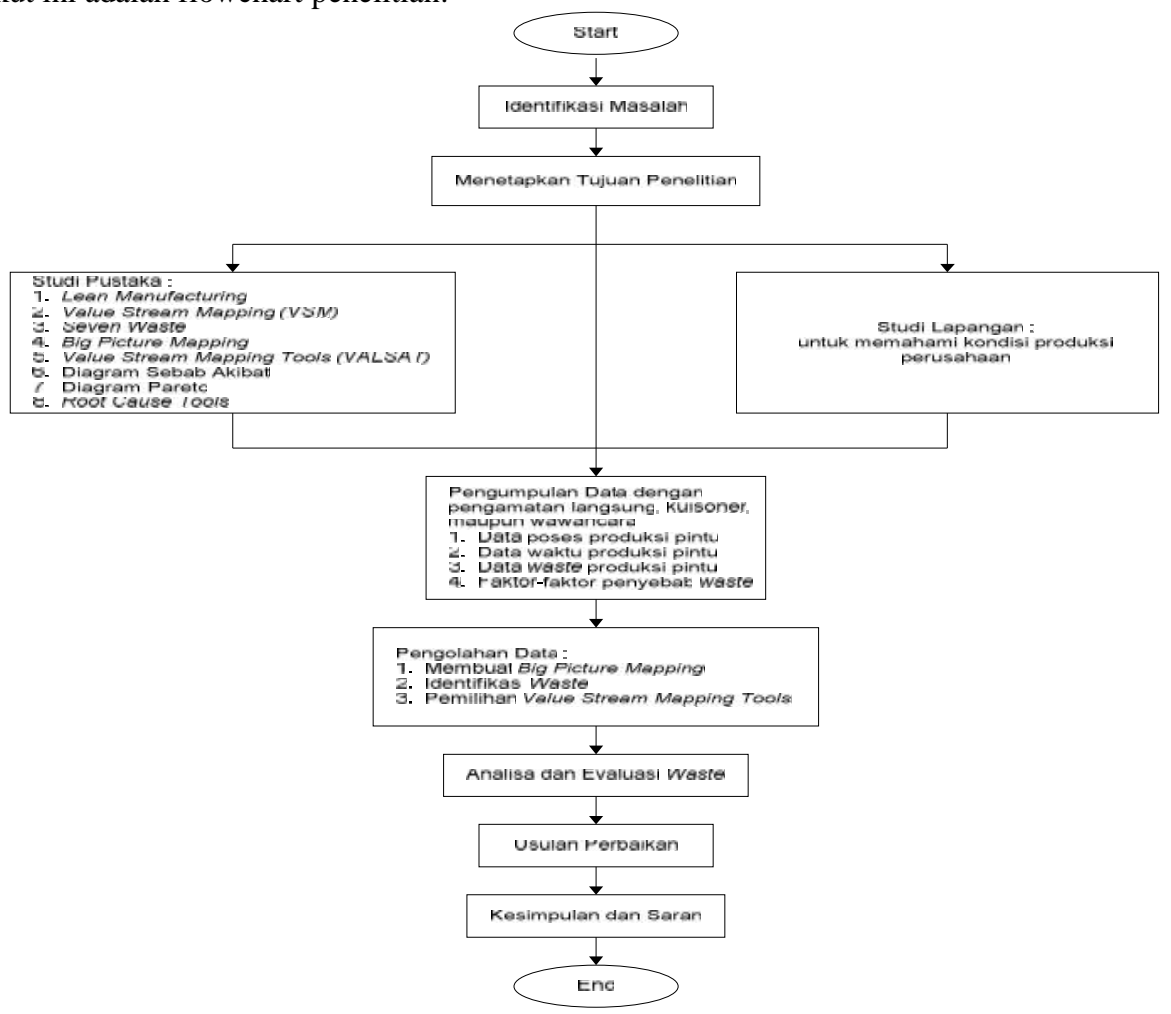

Flowchart Penelitian

\section{HASIL DAN PEMBAHASAN}

\section{Big Picture Mapping}

Big picture mapping digunakan untuk menggambarkan secara lengkap aliran proses yang meliputi aliran fisik material dan aliran informasi yang menyertainya serta lead time yang dibutuhkan dari masingmasing proses yang terjadi. Tujuan dari big picture mapping adalah untuk membuat dan menyalurkan produk atau jasa kepada konsumen akhir. Rangkaian atau jaringan ini terbentang dari penambang bahan mentah (di bagian hulu) sampai retailer / toko (pada bagian hilir). 


\section{Aliran Material}

Dengan menggunakan aliran material tersebut peneliti dapat dengan mudah untuk mengambarkan setiap pergerakan sumber daya yang ada pada perusahaan.

1. Bahan baku kayu yang digunakan dikirim langsung dari Pulau Seram dan untuk bahan baku pembantu seperti lem kayu, paku kayu, cat melaminedapat dibeli dari toko-toko material yang ada di Kota Ambon, setelah itu bahan baku diletakkan didalam gudang.

Bahan Baku Produksi Pintu Minimalis Pada UD. Filkin

\begin{tabular}{|l|c|c|c|}
\hline Bahan Baku (Material) & Jenis & Satuan & Jumlah \\
\hline Kayu & Linggua / Besi & $\mathrm{m}^{3}$ & 5 \\
\hline Paku & & $\mathrm{Kg}$ & 10 \\
\hline Cat Melamine & Impra Melamine & $\mathrm{Klg}$ & 10 \\
\hline Thiner & Thiner Impala & $\mathrm{Klg}$ & 10 \\
\hline Lem Kayu & Lem Fox & Tube & 2 \\
\hline
\end{tabular}

2. Bahan baku diambil dari gudang dan disiapkan pada lantai produksi sesuai kebutuhan kemudian akan dilanjutkan dengan proses menghaluskan permukaan kayu yang tidak rata menggunakan mesin planer (mesin serut kayu). Setelah proses menghaluskan permukaan kayu akan dilanjutkan proses tahap kedua, dimana kayu tersebut dipotong menggunakan mesin somel (mesin gergaji kayu) serta dirakit menggunakan pak dan lem kayu agar pintu merekat kuat atau tidak mudah untuk terbelah. Proses selanjutnya diukir sesuai desain pintu yang akan dibuat oleh perusahaanmenggunakan mesin router dan bisa juga menggunakan tatah/pahat kayu.

3. Pada proses tahap akhir, akan dilakukan pengamplasan menggunakan mesin amplas kayu serta pengecatan menggunakan compressor dan spray gun.

4. Produk yang telah siap akan disimpan di gudang sebelum didistribusikan kepada konsumen yang memesan produk.

Aliran Informasi

Penggambaran aliran informasi ini diperoleh melalui proses wawancara pada setiap bagian yang berhubungan.

1. Konsumen akan memberikan informasi berupa pemesanan produk pada pemilik usaha (pemesanan produk dapat dilakukan via telephone ataupun face to face). Ketika konsumen dan pemilik usaha telah sepakat dengan pemesanan produk, maka owner akan melakukan pengecekan pada gudang perusahaan terkait ketersediaan bahan baku di gudang (apakah jumlah bahan baku mencukupi atau tidak untuk melakukan proses produksi produk, jika bahan baku tidak mencukupi, maka owner akan melakukan pemesanan untuk bahan baku).

2. Ketika bahan baku tidak mencukupi atau stok gudang mulai berkurang, maka owner akan melakukan pemesanan ke suplier untuk pengadaan bahan baku yang mulai berkurang di gudang perusahaan, agar ketika ada pesanan berikutnya di perusahaan, perusahaan tidak perlu mengeluarkan biaya tambahan untuk melakukan pengadaan bahan baku lagi.

3. Supplier akan mendrop setiap pemesanan bahan baku ke gudang perusahaan sesuai dengan pemesanan dari owner.

4. Pemilik usaha dan konsumen akan membuat kesepakatan terhadap harga yang harus dibayar untuk produk yang dipesan dan waktu pengiriman produk.

5. Pemilik usaha akan memberikan informasi kepada setiap pekerjanya untuk membuat produk yang dipesan oleh konsumen sesuai dengan desain yang telah disepakati oleh kedua belah pihak.

6. Produk yang telah siap akan disimpan di gudang sebelum didistribusikan kepada konsumen yang memesan produk.

\section{Identifikasi Pemborosan (Waste)}

Salah satu langkah awal untuk memahami permasalahan yang terjadi pada UD. Filkin adalah dengan menggunakan waste workshop. Dimana waste workshop merupakan salah satu cara yang dilakukan untuk memperoleh informasi yang berkaitan dengan pemborosan pada proses produksi pintu.

\section{Identifikasi Waste Berdasarkan Diagram Pareto}

Berdasarkan hasil kuesioner maka dapat dilihat urutan waste yang terjadi pada proses produksi pintu dalam UD. Filkin. Pada gambar sebagai berikut : 


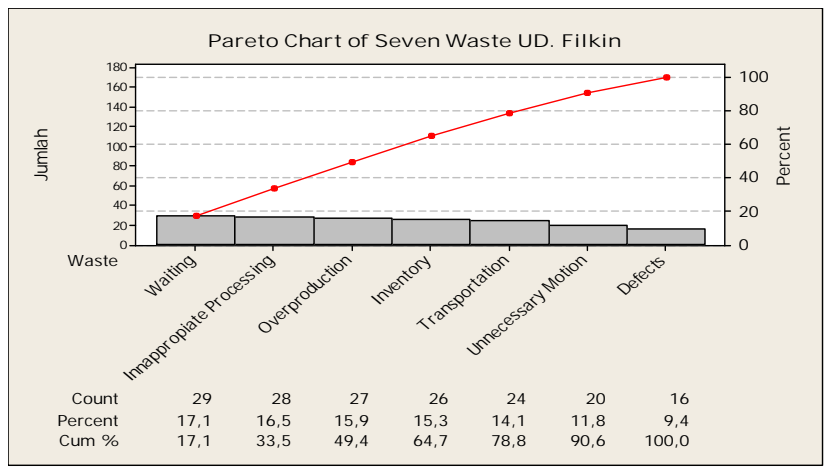

Diagram Pareto Seven Waste UD. Filkin

Berdasarkan Diagram pareto disini terlihat bahwa rangking tertinggi adalah jumlah Waste Waiting (29) dengan nilai presentasenya yaitu $(17,1 \%)$. Berikutnya ada jumlah Waste Inapproproate Processing (28) dengan nilai presentasenya yaitu (16,5\%). Jumlah Waste Overproduction (17) dengan nilai presentasenya (15,9\%). Jumlah Waste Unnecessary Inventory (26) dengan nilai presentasenya (15,3\%). Jumlah Waste Transportation (24) dengan nilai presentasenya (14,1\%). Jumlah Waste Unnecessary Motion (20) dengan nilai presentasenya (11,8\%). Jumlah Waste Defects (16) dengan nilai presentasenya $(9,4 \%)$.

\section{Pemilihan Tools dengan Value Stream Mapping Tools (VALSAT )}

Berdasarkan skor rata-rata dari setiap pemborosan, langkah selanjutnya adalah menentukan detailed mapping tool yang sesuai dengan jenis pemborosan yang timbul pada proses produksi. Berikut ini merupakan tabel perhitungan VALSAT dan hasil perhitungan VALSAT :

Perhitungan dan Penentuan Penggunaan Tools

\begin{tabular}{|c|c|c|c|c|c|c|c|c|}
\hline \multirow{2}{*}{ Waste } & \multirow{2}{*}{ Bobot } & \multicolumn{9}{|c|}{ Detail Value Stream Mapping } \\
\cline { 2 - 8 } & PAM & SCRM & PVF & QFM & DAM & DPA & PSM \\
\hline Overproduction & 4,5 & 4,5 & 13,5 & - & 4,5 & 13,5 & 13,5 & - \\
\hline Waiting & 4,8 & 43,2 & 43,2 & 4,8 & - & 14,4 & 14,4 & - \\
\hline $\begin{array}{c}\text { Transportation } \\
\text { Pnappropiate }\end{array}$ & 4 & 36 & - & - & - & - & - & 4 \\
\hline $\begin{array}{c}\text { Unnecessing } \\
\text { Inventory }\end{array}$ & 4,7 & 42,3 & - & 14,1 & 4,7 & - & 4,7 & - \\
\hline Unnecessary Motion & 3,3 & 12,9 & 38,7 & 12,9 & - & 38,7 & 12,9 & 4,3 \\
\hline Defect & 2,7 & 29,7 & 3,3 & - & - & - & - & - \\
\hline Jumlah & & $\mathbf{1 7 1 , 3}$ & $\mathbf{9 8 , 7}$ & $\mathbf{3 1 , 8}$ & $\mathbf{3 3 , 5}$ & $\mathbf{6 6 , 6}$ & $\mathbf{4 5 , 5}$ & $\mathbf{8 , 3}$ \\
\hline
\end{tabular}

Hasil perhitungan VALSAT dapat dilihat pada tabel dibawah ini :

Perankingan VALSAT
\begin{tabular}{|c|c|c|}
\hline Tools & Total Skor & Rangking \\
\hline Process Activity Mapping & 171,3 & 1 \\
\hline Supply Chain Response Matrix & 98,7 & 2 \\
\hline Production Variety Funnel & 31,8 & 6 \\
\hline Quality Filter Mapping & 33,5 & 5 \\
\hline Demand Amplification Mapping & 66,6 & 3 \\
\hline Decission Point Analysis & 45,5 & 4 \\
\hline Physical Structure. & 8,3 & 7 \\
\hline
\end{tabular}

Berdasarkan hasil perhitungan VALSAT yang telah dilakukan, dapat dilihat bahwa tools yang dipakai untuk melakukan detail mapping adalah :

1. Process Activity Mapping, dengan nilai 171,3

2. Supply Chain Response Matrix, dengan nilai 98,7

3.

Identifikasi Value Stream Mapping Tools

1. Process Activity Mapping ( PAM )

Dari pengelompokan tersebut dapat diketahui aktifitas apasaja yang paling dominan terjadi pada lini produksi furniture UD.Filkin. 
Total Presentase Aktifitas VA, NVA, dan NNVA

\begin{tabular}{|c|c|c|}
\hline Aktifitas & Jumlah & $\begin{array}{l}\text { Waktu } \\
\text { (Menit) }\end{array}$ \\
\hline Operation & 12 & 825 \\
\hline Transportation & 4 & 270 \\
\hline Inspection & 8 & 40 \\
\hline Storage & 1 & 705 \\
\hline Delay & 1 & 120 \\
\hline $\mathrm{VA}$ & 10 & 675 \\
\hline NVA & 12 & 895 \\
\hline NNVA & 4 & 390 \\
\hline $\begin{array}{l}\text { TOTAL WAKTU } \\
\text { (minute) }\end{array}$ & \multicolumn{2}{|c|}{1960} \\
\hline$\% \mathrm{VA}$ & \multicolumn{2}{|c|}{34,44} \\
\hline$\% \mathrm{NVA}$ & \multicolumn{2}{|c|}{45,66} \\
\hline$\%$ NNVA & \multicolumn{2}{|c|}{19,90} \\
\hline
\end{tabular}

Jika perhitungan waktu dikurangi dengan aktifitas -aktifitas inti dari proses produksi, maka waktu yang diperlukan hanya membutuhkan waktu sebanyak 1225 menit atau sekitar 20:25:00 jam atau sekitar 3 hari kerja.

Aktifitas Produksi Pintu Minimalis UD. Filkin

\begin{tabular}{|c|c|c|c|c|c|}
\hline & Operation & Transportation & Inspection & Storage & Delay \\
\hline Jumlah Aktifitas & 12 & 4 & 8 & 1 & 1 \\
\hline Presentase (\%) & 46,15 & 15,38 & 30,77 & 3,85 & 3,85 \\
\hline
\end{tabular}

\section{Pembuatan Supply Chain Response Matrix (SCRM)}

Days physical stock terbesar terletak pada area gudang bahan baku thinner yaitu 6,28 hari. Pada tabel 6 dibawah ini peniliti akan menjelaskan days physical stock untuk kedua bahan baku tersebut.

Days Physical Stock Dan Lead Time Raw Material

\begin{tabular}{|c|c|c|c|c|c|c|}
\hline No & Keterangan & Bahan Baku & $\begin{array}{c}\text { Days Phisical } \\
\text { Stock }\end{array}$ & $\begin{array}{c}\text { Lead } \\
\text { times }\end{array}$ & Kumulatif days & $\begin{array}{c}\text { Kumulatif lead } \\
\text { times }\end{array}$ \\
\hline 1 & $\begin{array}{c}\text { Area } \\
\text { Penyimpanan } \\
\text { Bahan Baku }\end{array}$ & $\begin{array}{c}\text { Kat Melamin } \\
\text { Thiner) }\end{array}$ & 8,63 & 1 & 8,63 & 1 \\
\hline 2 & Area Produksi & 1,37 & 3 & 1,37 & 3 \\
\hline 3 & $\begin{array}{c}\text { Area } \\
\text { Penyimpanan } \\
\text { Barang Jadi }\end{array}$ & 1,25 & 4 & 1,25 & 4 \\
\hline \multicolumn{2}{|c|}{ Total } & & 11,25 & 8 \\
\cline { 5 - 7 }
\end{tabular}

Berikut ini merupakan grafik SCRM :

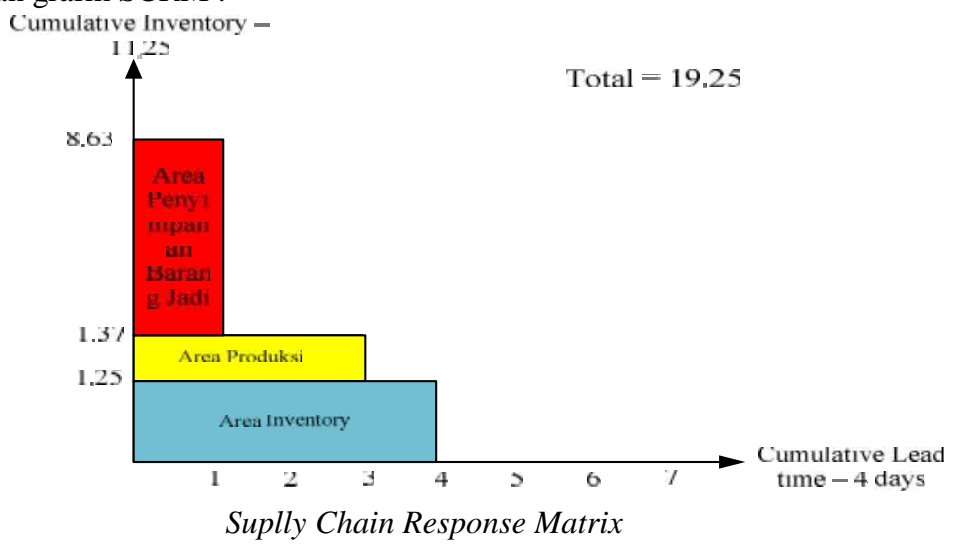




\section{Analisis dan Pembahasan}

\section{Analisa Pemborosan yang Terjadi Sepanjang Whole Stream Proses Produksi Pintu}

1. Analisa WasteOverproduction

Dalam pemborosan ini, produk yang dicetak lebih dari jumlah permintaan, dikarenakan ketika ada produk yang cacat maka pekerja tidak membuat ulang pintu agar tidak mengeluarkan biaya tambah untuk membuat produk tersebut. Namun ketika produk yang dicetak berlebihan maka akan mengurangi stock bahan baku pada lantai produksi.

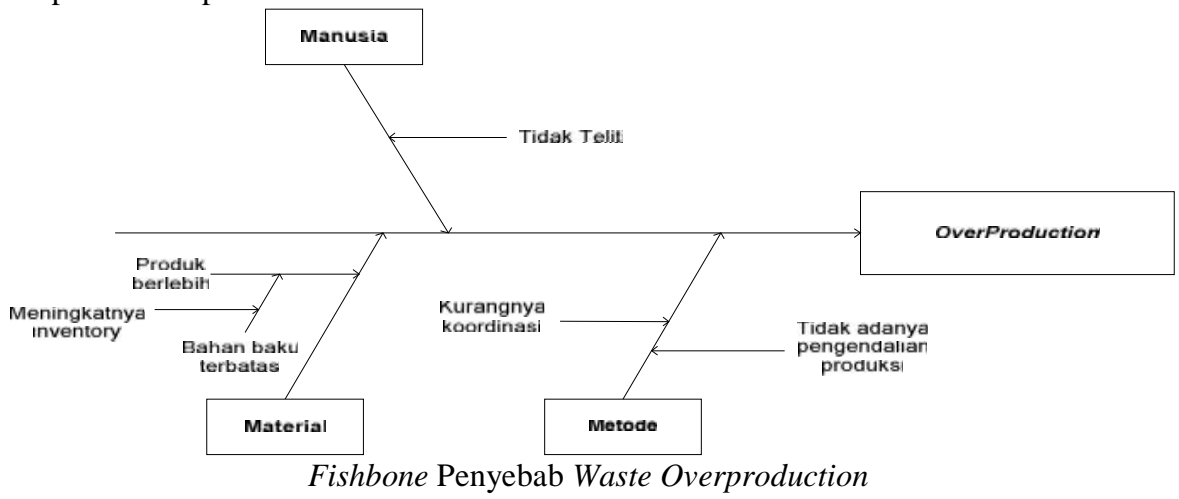

\section{Analisa WasteWaiting}

Pada UD. Filkinwaste waiting disebabkan oleh beberapa faktor, yaitu :

- Kurangnya keahlian pada pekerja.

- Material menunggu untuk dikerjakan.

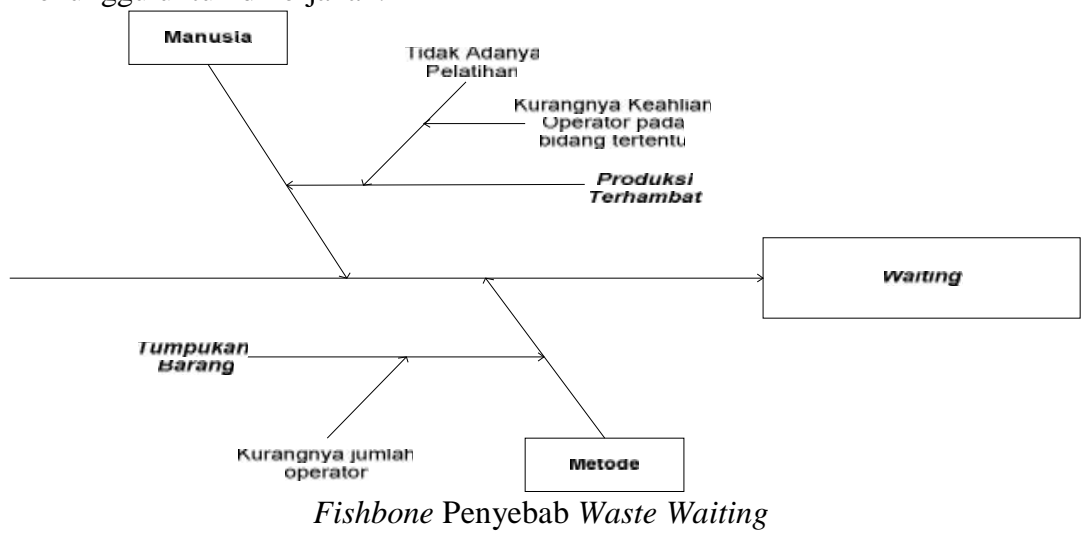

\section{Analisa WasteTransportation}

Pada UD. Filkin waste transportation disebabkan oleh beberapa faktor, yaitu :

- Jarak perpindahan terlalu jauh sehingga menyebabkan kelelahan pada pekerja untuk memindahkan material.

- Tata ruang / lay-out pabrik yang tidak rapih sehingga menyebabkan ruang gerak untuk pekerja terbatas.

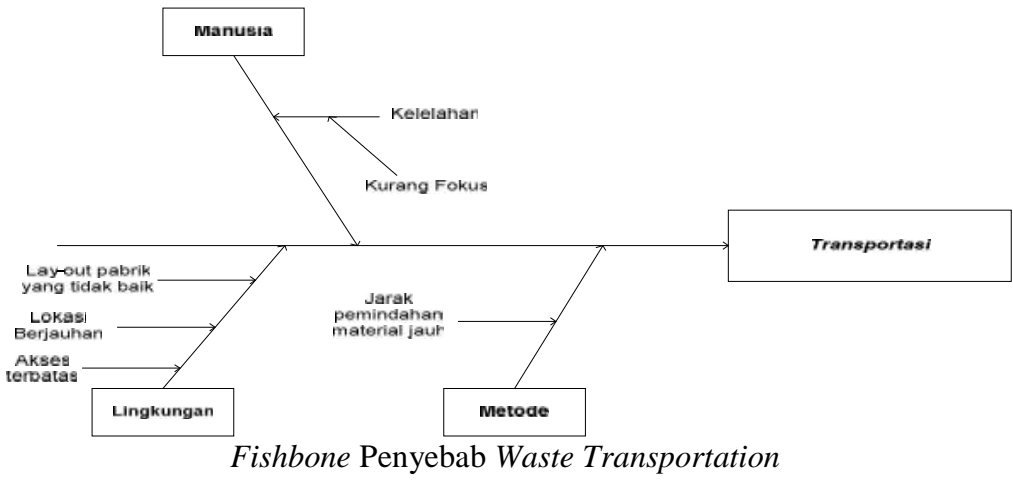




\section{Analisa WasteInnappropiate Processing}

Dalam hal ini wasteinappropriate processing yang ditemui pada lantai produksi UD. Filkin adalah salah komunikasi antara konsumen dengan pekerja, maka terjadi kesalahan produksi sehingga pekerja harus kembali membuat produk terebut.

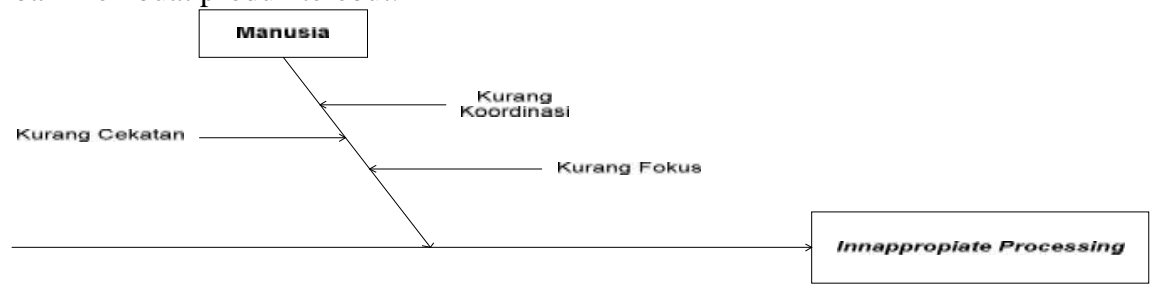

Fishbone Penyebab Waste Inappropriate processing

\section{Analisa Waste Unnecessary Inventory}

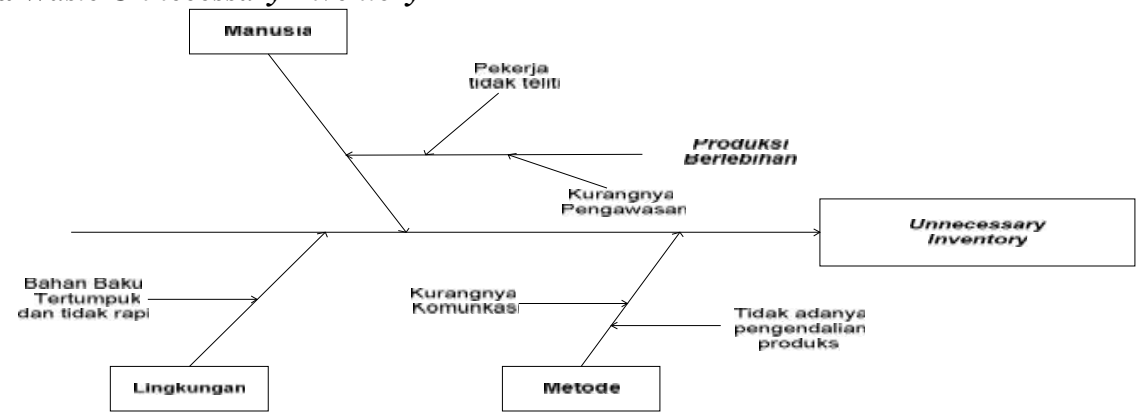

Fishbone Penyebab Waste Inventory

\section{Analisa Waste Unnecessary Motion}

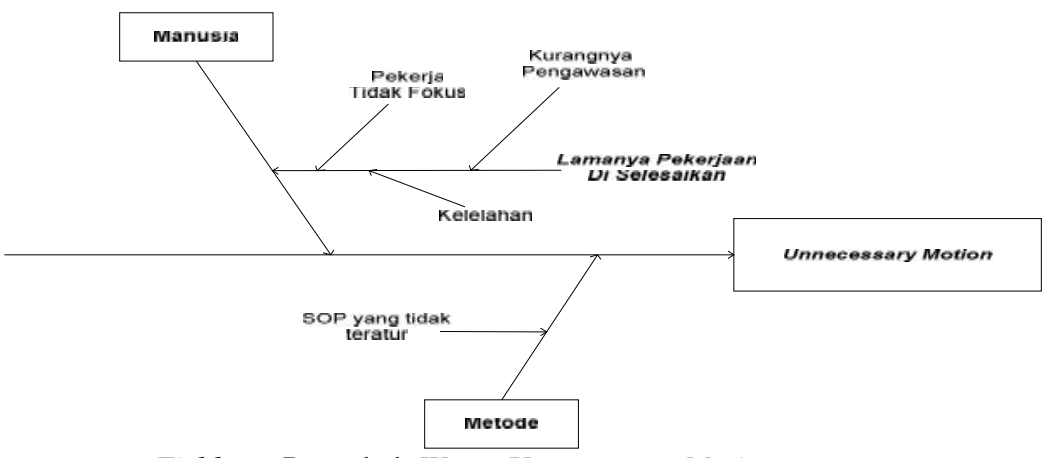

\section{Analisa Waste Defect}

Fishbone Penyebab Waste Unnecessary Motion

Pada UD. Filkin waste defect disebabkan oleh salah komunikasi antara konsumen dengan pekerja, maka terjadi kesalahan produksi sehingga pekerja harus kembali membuat produk terebut.

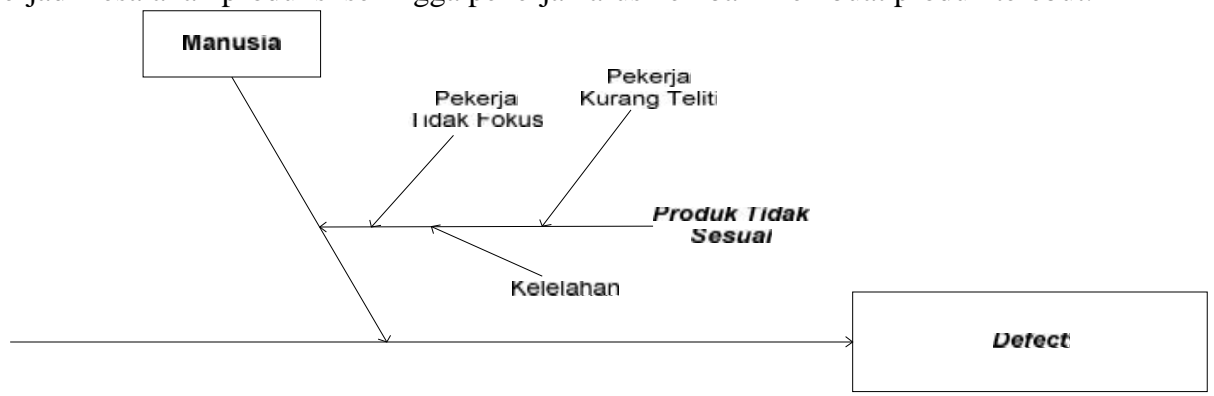

Fishbone Penyebab Waste Defect 


\title{
Analisa Seven Waste Dengan Menggunakan Root Cause Analysis Waste
}

\author{
a. Overproduction
}

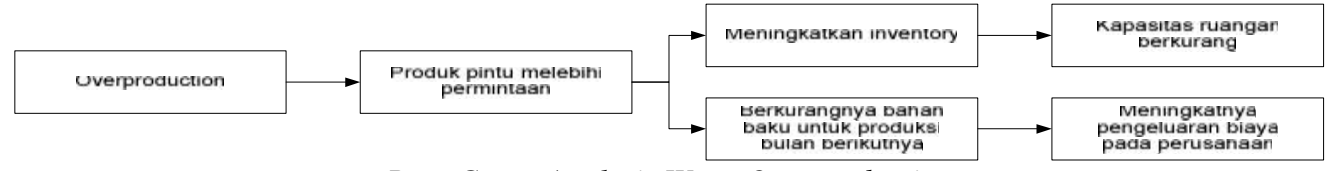

Root Cause Analysis WasteOverproduction

Waste overproduction terjadi dikarenakan pada lantai produksi, perusahaan mencetak atau membuat produk melebihi permintaan pasar, yang mengakibatkan terjadinya penumpukan pada area gudang perusahaan dan persediaan bahan baku untuk bulan berikutnya berkurang. Berkurangnya persediaan bahan baku digudang perusahaan, akan mengakibatkan perusahaan harus mengeluarkan biaya untuk membeli bahan bahan baku untuk persediaan bulan berikutnya. Pembelian bahan baku perbulannnya adalah 5 kubik kayu. Dikarenakan jika perusahaan memesan bahan baku yang banyak, bukan hanya berpengaruh terhadap kapasitas ruang saja, melainkan melainkan menghindari terjadinya kerugian material. Contohnya yaitu kayu jika terlalu lama digudang maka kayu akan dimakan oleh rayap. Hal itu sangat dihindari, maka perusahaan hanya menyediakan bahan baku secukupnya saja, agar tidak terjadi penumpukan diarea gudang.

b. Waiting

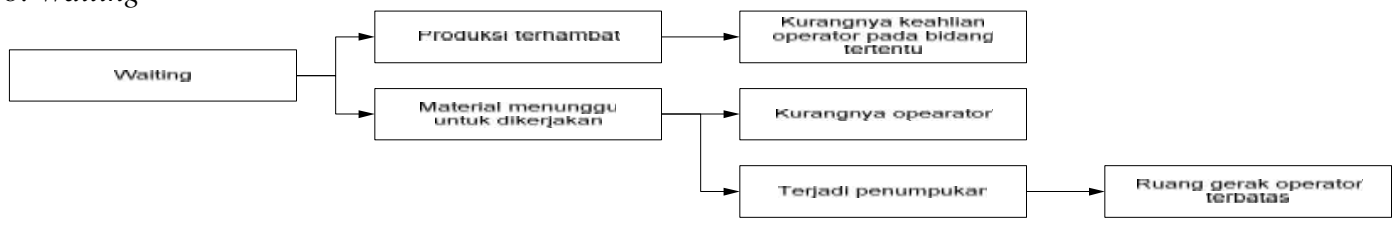

Root Cause Analysis WasteWaiting

Waste waiting menyebabkan proses produksi terhambat. Dimana, terhambatnya proses produksi diakibatkan oleh operator atau para tukang dilantai produksi. Hal ini sangat menggangu dalam suatu proses produksi karena akan meningkatkan lead time pada perusahaan tersebut. Jika lead time meningkat maka, perusahaan akan merugi dari segi waktu. Misalkan perusahaan biasanya membutuhkan waktu untuk produksi produk "A" adalah 4 hari, tetapi karena perusahaan kekurangan operator yang ahli pada bagian produksi, maka perusahaan akan memperpanjang waktu produksinya. Hal ini sangat dihindari, dikarenakan jika ketepatan waktu tidak sesuai dengan kesepakan antara produsen dan konsumen, maka perusahaan akan kehilangan pelanggan, atau kepuasan pelanggan akan menurun. Meskipun tidak semua terjadi demikian, tetapi perusahaan harus tetap mengedepankan nama baik perusahaan dan kepuasan pelanggan. Dan untuk faktor yang menyebabkan terjadinya waste waiting berikutnya adalah terjadinya penumpukan diarea produksi karena kurangnya jumlah operator dilantai produksi. terjadinya penumpukan material ataupun produk setengah jadi akan membuat para pekerja tidak nyaman untuk melakukan setiap aktifitas produks dikarenakan ruang gerak yang sangat terbatas. Hal ini harus sangat dihindari agar pekerja lebih produktif dalam bekerja untuk mendapatkan hasi produksi yang baik.

\section{c. Transportation}

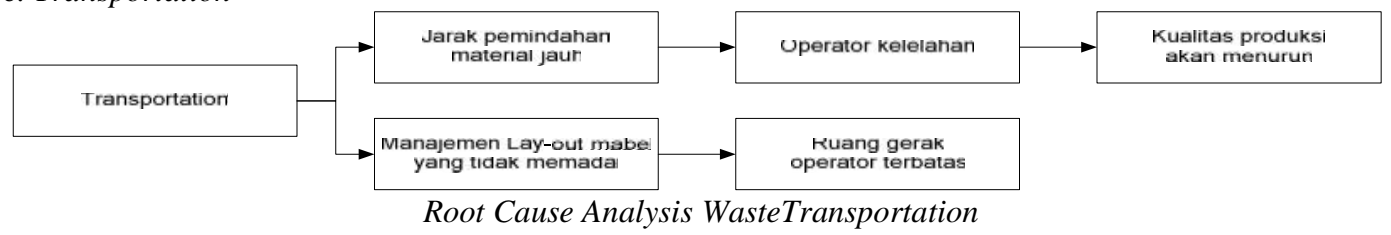

Waste transportation disebabkan oleh jarak pemindahan material yang jauh dan layout mabel yang tidak sesuai. Untuk faktor yang pertama, jarak pemindahan material yang jauh sangat berpengaruh besar terhadap produk yang dihasilkan. Dikarenakan jika operator mengerjakan lebih dari 1 pekerjaan di lantai produksi maka operator akan kelelahan, dan untuk melakukan tugas utama mereka, operator akan mengalami kelelahan dan menjadi tidak fokus untuk melakukan proses produksi. Jika terjadi hal ini terjadi maka, akan berpengaruh terhadap hasil produksinya. Contohnya, ukuran pintu yang tidak sesuai, ukiran yang dibuat tidak sesuai dengan permintaan pelanggan ataupun hasil packagingnya kurang rapih 
dan sebagainya. Hal ini harus dihindari agar performa dari perusahaan tetap terjaga kualitas produknya. Untuk itu perusahaan harus tetap memperhatikan hal seperti ini, agar operator tetap konsisten terhadap pekerjaan yang sesuai dengan keahliannya. Jika hal tersebut mendesak, yang mengharuskan pekerja untuk melakukan 2 pekerjaan dilantai produksi, maka perusahaan harus memberikan insentif tambahan bagi para pekerja, agar mereka lebih semangat dalam bekerja dan tetap konsisten. Dan untuk masalah layout perusahaan yang tidak memadai, perusahaan harus mengatur ulang layout dari pabrik tersebut, agar pada saat proses produksi berlangsung, para operator atau pekerja merasa nyaman dan lebih leluasa dalam melakukan pekerjaan meraka.

d. Innappropiate Processing

\begin{tabular}{|c|c|c|c|}
\hline $\begin{array}{c}\text { Innappropiate } \\
\text { Processing }\end{array}$ & $\begin{array}{l}\text { Salah komunikasj } \\
\text { operator dengan } \\
\text { konsumen }\end{array}$ & $\begin{array}{l}\text { Operator membuat } \\
\text { ulang produk }\end{array}$ & $\begin{array}{c}\text { Meningkatkan } \\
\text { pengeluaran biaya } \\
\text { pada perusahaan }\end{array}$ \\
\hline
\end{tabular}

Waste Innappropiate Processing disebabkan oleh kurangnya komunikasi antara produsen dan konsumen. Dimana jika hal ini terjadi perusahaan akan melakukan pengulangan produksi, yang dapat mengakibatkan berkurangannya persediaan bahan baku diarea gudang perusahaan dan terjadi penumpukan diarea gudang perusahaan. Jika perusahaan mengalami hal seperti ini, maka perusahaan juga akan mengeluarkan biaya tambahan baik untuk biaya bahan baku, maupun mengeluarkan biaya tambahan untuk membayar operator,transportasi dan lainnya. Untuk itu, ketika konsumen melakukan pemesan terhadap produk yang akan dibuat oleh perusahaan, perusahaan perlu memastikan bahwa produk yang akan dibuat harus sesuai dengan apa yang pelanggan inginkan atau harus ada kesepakatan dari kedua belah pihak, baik dalam desain yang diinginkan ataupun dalam penetapan harga per tiap produk agar tidak terjadi kerugian material dan biaya lainnya.

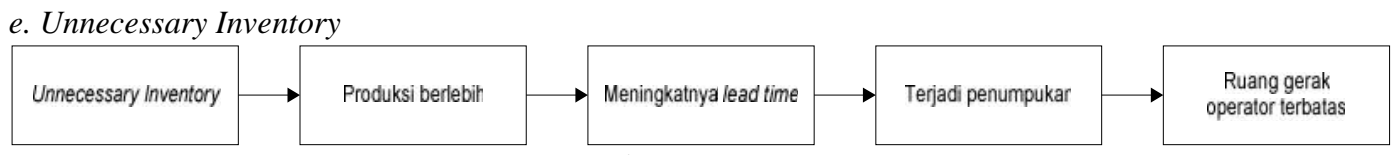

Root Cause Analysis WasteUnnecessary Inventory

Waste inventory disebabkan oleh produksi produk yang berlebihan pada area produksi yang mengakibatkan terjadi penumpukan dilantai produksi. proses produksi yang berlebih mengakibatkan lead time dalam satu proses meningkatkan. Misalkan seperti yang telah dijelaskan pada analisis root causes analysis untuk waste sebelumnya, bahwa jika perusahaan memproduksi barang "A" sebanyak 160 potong dengan total lead timenya 8 jam, tetapi perusahaan memproduksi lebih produk "A" sebanyak 180 maka waktu yang dibtuhkan dalam satu proses produksi akan meningkat dan membuthkan waktu yang lama. Alasanmengapa perusahaan memproduksi lebih yaitu untuk mengurangi biaya tambahan untuk produksi ulang produk. Tetapi jika hal itu terjadi secara berulang-ulang maka perusahaan akan rugi akan material dan lain-lain. Kerugian ini harus dihindari atau juga harus dikurangi oleh perusahaan. Perusahaan harus melakukan settingan awal sebelum melakukan proses produksi agar dalam produksinya perusahaan mencetak atau memproduksi produk sesuai pada pesanan, atau perusahaan mencetak produk tambahan hanya $0.5 \%$ dari pesanan agar juga tidak berpengaruh terhadap inventory dari perusahaan (penumpukan pada area produksi)

\section{f. Unnecessary Motion}

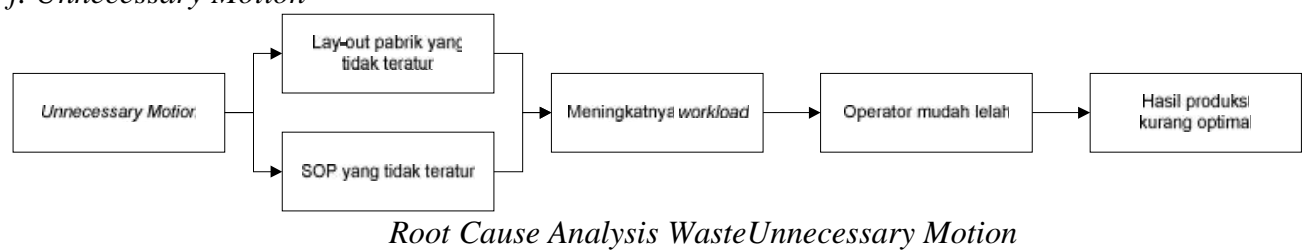

WasteUnnecessary Motion disebabkan oleh dua faktor yaitu layout area produksi dan SOP yang tidak teratur. Dimana dua faktor tersebut akan berpengaruh pada workload (beban kerja dalam suatu posisi dan kebutuhan jumlah orang untuk mengisi posisi tersebut). Dimana ketika SOP yang sudah dibuat diperusahaan tersebut tidak dijalankan sesuai dengan ketentuan SOP perusahaan, maka dalam proses produksi yang terjadi di area produksi berjalan tidak teratur atau tidak sesuai. Pekerja dilantai produksi 
akan melakukan aktifitas atau kegiatan produksi yang dapat mempengaruhi performa kerja mereka, entah itu mereka mengalami kelelahan ataupun mengalami cedera. Jika hal itu terjadi pada setiap operator maka hasil dari produksi menjadi kurang optimal. Untuk itu perusahaan haruslah melakukan setiap proses produksi, sesuai dengan SOP yang sudah ditetapkan oleh perusahaan agar terhindar dari hal-hal yang dapat merugikan perusahaan

g. Defect

\begin{tabular}{|c|c|c|c|}
\hline Derect & $\begin{array}{l}\text { Salan komunikas } \\
\text { operator dengan } \\
\text { Konsumnen }\end{array}$ & Produk cacal & $\begin{array}{l}\text { Operator membuat } \\
\text { produk ulang }\end{array}$ \\
\hline
\end{tabular}

Root Cause Analysis WasteDefect

Waste deffect disebabkan olehsalah komunikasi operator dengan konsumen. Jika perusahaan mengalami hal seperti ini, maka perusahaan harus memperbaiki produk tersebut sehinggadapatmenyebabkan mengeluarkan biaya tambahan baik untuk biaya bahan baku, maupun mengeluarkan biaya tambahan untuk membayar operator,transportasi dan lainnya

\section{Rekomendasi Perbaikan}

Rekomendasi perbaikan akan dilakukan berdasarkan hasil penggambaran pemborosan pada whole stream sistem produksi, hasil analisa. Adapun rekomendasi perbaikan yang dapat dilakukan adalah sebagai berikut :

\begin{tabular}{|c|c|c|c|c|}
\hline \multicolumn{5}{|c|}{ Root Cause dan Rekomendasi Perbaikan } \\
\hline Waste & (Root Cause) & Dampak & Rekomendasi & $\begin{array}{l}\text { Hasil Yang } \\
\text { Diharapkan }\end{array}$ \\
\hline Overproduction & $\begin{array}{l}\text { Produk pintu } \\
\text { melebihi permintaan }\end{array}$ & $\begin{array}{l}\text { - Terjadi penumpukan } \\
\text { yang menyebabkan } \\
\text { berkurangnya } \\
\text { kapasitas ruangan } \\
\text { - Berkurangnya bahan } \\
\text { baku } \\
\text { - Meningkatnya biaya } \\
\text { pengeluaran }\end{array}$ & $\begin{array}{l}\text { Melakukan } \\
\text { perencanaan ulang } \\
\text { terhadap produk } \\
\text { yang akan dibuat, } \\
\text { yang sesuai dengan } \\
\text { permintaan pasar }\end{array}$ & $\begin{array}{l}\text { - Meminimumkan } \\
\text { biaya yang } \\
\text { dikeluarkan oleh } \\
\text { pabrik. } \\
\text { - Meminimalkan } \\
\text { jumlah bahan } \\
\text { produk yang tidak } \\
\text { terpakai } \\
\end{array}$ \\
\hline Waiting & $\begin{array}{l}\text { - Produksi } \\
\text { terhambat } \\
\text { - Material } \\
\text { menunggu untuk } \\
\text { dikerjakan } \\
\text { - Kurangnya } \\
\text { jumlah pekerja }\end{array}$ & $\begin{array}{l}\text { - Kurangnya keahlian } \\
\text { pekerja pada bidang } \\
\text { tertentu sehingga } \\
\text { membuat produksi } \\
\text { terhambat } \\
\text { - Kurangnya pekerja } \\
\text { sehingga material } \\
\text { menunggu untuk } \\
\text { dikerjakan dan dapat } \\
\text { mengalami } \\
\text { penumpukan yang } \\
\text { membuat ruang gerak } \\
\text { opetaror terbatas }\end{array}$ & $\begin{array}{l}\text { - Pelatihan untuk } \\
\text { pekerja yang lain } \\
\text { sehingga jika ada } \\
\text { pekerja yang } \\
\text { tidak hadir bisa } \\
\text { di ambil alih } \\
\text { pekerjaannya } \\
\text { agar tidak terjadi } \\
\text { produksi } \\
\text { terhambat } \\
\text { - Penambahan } \\
\text { pekerja pada } \\
\text { bagian } \\
\text { pengecatan agar } \\
\text { tidak terjadi } \\
\text { penumpukan }\end{array}$ & $\begin{array}{l}\text { - Meminimumkan } \\
\text { proses produksi } \\
\text { yang terhambat } \\
\text { - Dapat } \\
\text { menyesuaikan } \\
\text { banyanknya } \\
\text { opeartor sesuai } \\
\text { tingkat } \\
\text { pekerjaannya }\end{array}$ \\
\hline Transportation & $\begin{array}{l}\text { - Jarak pemindahan } \\
\text { material jauh } \\
\text { - Manajemen Lay- } \\
\text { out pabrik yang } \\
\text { tidak memadai }\end{array}$ & $\begin{array}{l}\text { - Pekerja kelelahan } \\
\text { yang dapat } \\
\text { menyebabkan kualitas } \\
\text { produksi akan } \\
\text { menurun } \\
\text { - Ruang gerak opeartor } \\
\text { terbatas }\end{array}$ & $\begin{array}{l}\text { Perbaikan lay-out } \\
\text { pabrik }\end{array}$ & $\begin{array}{l}\text { Pekerja tidak } \\
\text { kelelahan dan dapat } \\
\text { mengerjakan } \\
\text { pekerjaannya dengan } \\
\text { konsisten dan } \\
\text { mengurangi kesalahan } \\
\text { dalam bekerja }\end{array}$ \\
\hline $\begin{array}{l}\text { Innappropiate } \\
\text { Processing }\end{array}$ & $\begin{array}{l}\text { Salah komunikasi } \\
\text { pekerja dengan } \\
\text { konsumen }\end{array}$ & $\begin{array}{l}\text { Pekerja membuat } \\
\text { produk ulang yang } \\
\text { dapat meningkatkan } \\
\text { pengeluaran biaya pada } \\
\text { pabrik }\end{array}$ & $\begin{array}{l}\text { Meningkatkan pola } \\
\text { pemahaman } \\
\text { pekerja terhadap } \\
\text { keinginan } \\
\text { konsumen }\end{array}$ & $\begin{array}{l}\text { Meminimumkan biaya } \\
\text { dan produk yang tidak } \\
\text { sesuai yang dapat } \\
\text { ditimbulkan }\end{array}$ \\
\hline
\end{tabular}




\begin{tabular}{|c|c|c|c|c|}
\hline Waste & (Root Cause) & Dampak & Rekomendasi & $\begin{array}{c}\text { Hasil Yang } \\
\text { Diharapkan }\end{array}$ \\
\hline $\begin{array}{l}\text { Unnecessary } \\
\text { Inventory }\end{array}$ & Produk berlebih & $\begin{array}{l}\text { Meningkatnya lead time } \\
\text { dan terjadi penumpukan } \\
\text { pada lantai produksi } \\
\text { juga dikarenakan } \\
\text { gudang sudah penuh }\end{array}$ & $\begin{array}{l}\text { - Mengatur ulang } \\
\text { sistem alur } \\
\text { produksi yang } \\
\text { dijalankan oleh } \\
\text { mebel. } \\
\text { - Mengatur ulang } \\
\text { kapasitas gudang } \\
\text { agar dapat } \\
\text { dibedakan } \\
\text { produk yang } \\
\text { baru dan lama } \\
\text { yang masih bisa } \\
\text { digunakan, agar } \\
\text { tidak terjadi } \\
\text { penumpukan } \\
\text { juga pada lantai } \\
\text { produksi }\end{array}$ & $\begin{array}{l}\text { - Memperkecil } \\
\text { kemungkinan } \\
\text { terhadap meluapnya } \\
\text { jumlah inventory di } \\
\text { gudang } \\
\text { - Lebih banyak ruang } \\
\text { gerak pada gudang } \\
\text { dan lantai produksi }\end{array}$ \\
\hline $\begin{array}{c}\text { Unnecessary } \\
\text { Motion }\end{array}$ & $\begin{array}{l}\text { - Lay-out pabrik } \\
\text { yang tidak teratur } \\
\text { - SOP (Standar } \\
\text { Operational } \\
\text { Procedure) yang } \\
\text { tidak teratur }\end{array}$ & $\begin{array}{l}\text { - Meningkatnya } \\
\text { workload } \\
\text { - Pekerja mudah lelah } \\
\text { - Hasil produksi kurang } \\
\text { optimal }\end{array}$ & $\begin{array}{l}\text { - Mengatur ulang } \\
\text { lay-out pabrik } \\
\text { - Penerapan SOP } \\
\text { (Standar } \\
\text { Operational } \\
\text { Procedure) bagi } \\
\text { setiap pekerja }\end{array}$ & $\begin{array}{l}\text { - Mengurangi tingkat } \\
\text { kelelahan bagi } \\
\text { setiap pekerja agar } \\
\text { pekerja dapat } \\
\text { melakukan tugasnya } \\
\text { lebih optimal dan } \\
\text { fokus pada } \\
\text { pekerjaannya } \\
\text { - Proses produksi } \\
\text { yang dilakukan } \\
\text { akan menjadi lebih } \\
\text { efektif dan lebih } \\
\text { efisien } \\
\end{array}$ \\
\hline Defects & $\begin{array}{l}\text { Salah komunikasi } \\
\text { pekerjadengan } \\
\text { konsumen }\end{array}$ & Produk cacat & $\begin{array}{l}\text { Meningkatkan pola } \\
\text { pemahaman } \\
\text { pekerja terhadap } \\
\text { keinginan } \\
\text { konsumen }\end{array}$ & $\begin{array}{l}\text { Berkurangnya waktu } \\
\text { penyelesaian yang } \\
\text { diinginkan }\end{array}$ \\
\hline
\end{tabular}

\section{KESIMPULAN}

Berdasarkan hasil penelitian yang telah dilakukan pada UD. Filkin dapat diambil kesimpulan dari penelitian ini adalah sebagai berikut :

1. Faktor penyebab adanya waste waiting yaitu kurangnya pekerja serta keahlian pada pekerja yang lain. Untuk penyebab adanya waste innappropiateprocessing yaitu terjadinya salah komunikasi antara konsumen dengan pekerja. Dan untuk penyebab adanya waste overproduction yaitu produk yang dibuat lebih dari jumlah permintaan.

2. Penerapan Lean Manufacturing dapat memberikan pengurangan untuk waste waiting awal sebesar $17,1 \%$ menjadi $13,73 \%$. Untuk waste innappropiateprocessing awal sebesar $16,5 \%$ menjadi $9,13 \%$. Dan untuk waste overproduction awal sebesar $15,9 \%$ menjadi $10,53 \%$.

\section{DAFTAR PUSTAKA}

Ariani, Dorothea Wahyu (2004) "Pengendalian Kualitas Statistik (Pendekatan Kuantitatif dalam Manajemen Kualitas)" Edisi Satu. Penerbit: ANDI OFFSET, Yogyakarta.

Batubara, S., \& Halimuddin, R. A. (2016). Penerapan Lean Manufacturing Untuk Meningkatkan Kapasitas Produksi Dengan Cara Mengurangi Manufacturing Lead Time Studi Kasus: PT. Oriental Manufacturing Indonesia. Jurnal Penelitian Dan Karya Ilmiah Lembaga Penelitian Universitas Trisakti, 1(1), 49-56.

Gaspersz, Vincent. (2007). Lean Six Sigma For Manufacturing and Service Industries. Jakarta : Gramedia Pustaka Utama.

Hines, P., \& Rich, N. (2008). Matrix Seven Tools dan Seven Waste, Matrix Seleksi Untuk Pemilihan VALSAT. 
Hobbs, Dennis P (2004). Lean Manufacturing Implementation : A Complete Execution Manual for Any Size Manufacturer. Florida : J. Ross Publishing, Inc.

Khannan, M. S. A., \& Haryono, H. (2015). Analisis Penerapan Lean Manufacturing untuk Menghilangkan Pemborosan di Lini Produksi PT Adi Satria Abadi. Jurnal Rekayasa Sistem Industri, 4(1), 47-54.

Pujawan. (2002). Lima Prinsip Pendekatan Lean Pada Toyota Production System.

Shingo, Shiego. (1990). A Study of the Toyota Production System. USA: Andrew P. Dillon Productivity Press

Widjaja, F. T., \& Halim, S. (2015). Penerapan Value Stream Mapping untuk Allocation Planning di PT. X. Jurnal Titra, 3(2), 135-142. 